\title{
EVALUACIJA EVALUACIJE NA VISOKOŠKOLSKIM USTANOVAMA $^{1}$
}

Evaluacija na visokoškolskim ustanovama predstavlja složen proces koji treba da obuhvati sve dimenzije procesa vaspitanja i obrazovanja i sve njegove faze, i to sa stanovišta studenta, profesora, uslova procesa učenja, kvaliteta rada ustanove i karakteristika njenih interakcija sa društvenim okruženjem.U radu se najpre analiziraju metodološke premise pedagoških evaluativnih istrađživanja, kao specifičnih, dinamičnih i kompleksnih empirijskih istraživanja. Ova istraživanja moraju imati validnu teorijsku osnovu, i moraju ih orgnaizovati oni, koji poseduju relevantno pedagoško-metodološko obrazovanje.Polazeći od toga, da je kvalitetna evaluacija fundamentalni proces na osnovu kojeg se može procenjivati kvalitet obrazovanja i kreirati strategija njegovog unapređivanja na univerzitetskom nivou, problem istraživanja čiji se nalazi analiziraju u ovom radu, je utvrđivanje karakteristika evaluacije na visokoškolskim ustanovama i njena funkcionalnost.

Ključne reči: evaluacija, kvalitet obrazovanja, visokoškolska ustanova.

Evaluacija je proces, aktivnost koju je neophodno kreirati, dizajnirati, planirati, osmisliti i realizovati, proces koji mora da bude inkorporiran u sve faze učenja i vaspitno - obrazovnog rada, proces koji mora da ima standarde, indikatore za identifikaciju, utvrđivanje, deskripciju, analizu, selekciju i komparaciju informacija i činjenica, ili date vaspitno-obrazovne situacije, a koji obuhvata i sve učesnike tog vaspitno-obrazovnog proseca. Evaluacija je, pored toga, nemoguća bez dobro definisanih vaspitno-obrazovnih ciljeva i ishoda, koji predstavljaju izvorište indikatora i standarda za evaluaciju. I na kraju, evaluacija predstavlja proces donošenja vaspitno-obrazovnih odluka kojima se usmerava, vodi i kreira sam vaspitno-obrazovni rad.

Kao što su brojni pristupi u shvatanju i definisanju procesa pedagoške evaluacije, tako su različita i shvatanje njene svrhe:

- Proces koji prethodi odlučivanju, usmeren na identifikaciju , (Stufflebeam, 2001),

- Opis i procena vaspitno-obrazovnog procesa zasnovan na evaluativnim istraživanjima, (Stake, 2010),

cios@eunet.rs. Rad je nastao u okviru projekta 179010 Kvalitet i kompetentnost obrazovanog sistema u Evropskoj perspektivi, koji se realizuje uz finansijsku podršku Ministarstva prosvete i nauke Republike Srbije. 
- Utvrđivanje vrednosti vaspitno-obrazovnog programa, (Stake 2010),

- Utvrđivanje da li program podstiče na optimalni razvoj ličnosti, (Cohen, 2001),

- Utrvrđivanje da li su inovacije efikasnije od postojećeg programa, (Hammond, 2011),

- Obezbeđivanje relevantne informacije za donošenje pedagoških odluka, (Stuffelbaem, 1980),

- Omogućavanje izbora prave alternative u odlučivanju, (Alkin, 2004),

- Utvrđivanje nivoa ostvarenosti vaspitno-obrazovnog cilja ili operacionalizovanih vaspitno-obrazovnih zadataka. (Popham 2001).

U savremenoj literaturi o metodološkim pitanjima evaluacije u kojoj se razmatraju evaluaciona israživanja sistema ili programa u oblasti obrazovanja, dosledno se pravi razlika izmedju „formativnog“ $i$,sumativnog“ pristupa evaluaciji.

Ako je reč o evaluaciji sistema ili obrazovnog programa koji se tek razvija, a sama evaluacija predstavlja sastavni deo toga razvoja, onda se ona označava kao - formativna (Scriven, 1967). Sumativnom se naziva evaluacija već razvijenih sistema ili programa, koja podrazumeva sistematsko ispitivanje, ostvarenosti postavljenih ciljeva i komparativne prednosti u odnosu na alternativne programe.

Proces formativne evaluacione studije $u$ obrazovanju se može razčlaniti na:

- Identifikovanje zavisnih promenljivih (identifikovanje i specifikovanje ciljeva koji se obrazovnim programom žele ostvariti, odnosno identifikovanje promena koje se žele pomoću njega ostvariti)

- Operacionalno definisanje zavisnih - promenljivih

- Razvijanje instrumenata za merenje zavisnih (kriterijumskih) promenljivih

- Merenje zavisnih (kriterijumskih) promenljivih

- Obrada, analiza i tumečenje podataka dobijenih evaluacionim istraživanjima obrazovanja.

- Sumativna evaluaciona studija uključuje sledeće osnovne faze:

- Identifikovanje zavisnih promenljivih (identifikovanje ciljeva koji se žele postići)

- Operacionalno definisanje zavisnih promenljivih (prevodjenje formulacija ciljeva u operacionalne definicije)

- Razvijanje instrumenata za merenje zavisnih ( kriterijumskih) promenljivih

- Razvijanje i primena nacrta istraživanja (koji omoguća ispoljavanje efekata nezavisne promenljive)

- Prikupljenje, obrada, analiza i tumačenje podataka

Navedene faze mogu se i koncizno opisati:

1. Identifikovanje zavisnih promenljivih:

Kada se unosi neka inovacija u oblasti obrazovanja, učesnici u toj inovaciji , po pravilu,imaju u vidu više ciljeva odnosno ishoda - posledica koje očekuju. Stepen u kojem se tom inovacijom postižu postavljeni ciljevi, predstavlja merilo za ocenjivanje efikasnosti te inovacije. Stoga je u prvoj fazi evaluacionih istraživanja neophodno dobiti izričit, jasan i precizan odgovor na pitanje: „Sa kojim je ciljevima preuzeta ova intervencija“ tj. šta se datim obrazovnim procesima želi postići, koje se promene žele izazvati. Jezikom metodologije govoreći, nužno je 
identifikovati zavisne (kriterijumske) promenljive (tj. veličine na kojima se žele izazvati promene).

Zato identifikovanje pravih i značajnih zavisnih promenljivih često zahteva prethodno eksplorativno istraživanje. To istraživanje se obično izvodi na sledeći način: u prvoj fazi se prikupljaju podaci od neposrednih učesnika u procesu pomoću struktuiranog intervjua, ili upitnika, u kome se od njih zahteva da nevedu ciljeve, i njihovu specifikaciju prema postojećem ličnom sistemu vrednosti. Na taj način se dobija lista ciljeva ili svrha obrazovnog procesa. Pošto ti ciljevi nemaju medjusobno jednak značaj, upotrebom odredjene skale procene vrši se njihovo ocenjivanje i dobija se relativni značaj svakog od navedenih ciljeva. Ocenjivanje relativnog značaja ciljeva je veoma važno. jer se na taj način obezbedjuje uzimanje u obzir samo značajnih ciljeva obrazovno-vaspitnog procesa, odnosno, samo značajnih zavisnih promenljivih. Pored toga, da bi se pratila i utvrdila vrednost vaspitno-obrazovnog procesa na osnovu stepena u kojem se u njemu ostvaruju postavljenu ciljevi, mora se prethodno imati relevantan uvid u značaj postavljenih i mogućih ciljeva. Ovako identifikovanje i ocena relativnog značaja obrazovnih ciljeva, odnosno, zavisnih promenljivih u velikoj meri je zasnovano na konsenzusu.

2. Operacionalno definisanje zavisnih promenljivih

Identifikovanje zavisnih - kriterijumskih promenljivih u evaluacionim pedagoškim istraživanjima podrazumeva postavljanje hipoteze o tome da li intervencija utiče na promene zavisne promenljive. Da bi se ta hipoteza proverila, nužno je obezbediti mogućnost merenja zavisnih promenljivih, jer mi na osnovu uporedjivanja rezultata merenja zavisne promenljive zaključujemo o odnosu izmedju nezavisne i zavisne promenljive, odnosno o mogućem efektu nezavisne promenljive za zavisnu. Drugačije govoreći, nužno je opreracionalno definisanje zavisnih promenljivih. Operacionalno definisati zavisnu promenljivu znači, odrediti njeno značenje navodjenjem skupa operacija merenja. Operacionalno definisanje zavisnih promenljivih bi trebalo da nam omogući dobijanje odgovora na pitanje: „kako možemo videti da li su i u kojoj meri postignuti obrazovni ciljevi u procesu učenja“. Reč je dakle, o prevodjenju obrazovnih ciljeva u konkretne, i merljive indikatore. 3. Razvijanje instrumenata za merenje zavisnih (kriterijumskih) promenljivih.

Kada se zavisne promenljive i operacionalo definišu, potrebno je razviti merne instumente za njihovo merenje, tj. za merenje stepena u kojem se postavljeni obrazovni ciljevi ostvaruju.

Problemi merenja u evaluacionim pedagoškim istraživanjima su veoma složeni, pa je njihovom rešavanju potrebno posvetiti izuzetnu pažnju. Instrumenti za merenje koji se koriste u evaluacionom istraživanju, moraju imati zadovoljavajuće metrijske karakteristike: pouzdanost, valjanost, osetljivost i dr. Pouzdanost mernog instrumenta se grubo može odrediti kao funkcija slobode rezultata merenja koji se dobijaju tim instrumentom, od slučajnih grešaka. Slučajna greška merenja je takva greška neke veličine pod relativno konstantim uslovima, čija aritmetička sredina, pri povećanju broja merenja teži ka beskonačnom limesu, koji je jednak nuli. 
Valjanost mernog instrumenta se odnosi na stepen u kome su rezultati merenja dobijeni tim isntrumentom slobodni i od slučajnih i od sistematskih grešaka. Pod sistematskim greškama merenja se podrazumevaju one greške merenja nekog svojstva u relativno konstantnim uslovima, čija aritmetička sredina, kada se broj merenja povećava ka beskonačnom, teži nekom limesu koji nije jednak nuli.

Bez pouzdanosti i valjanosti mernih instrumenata kojima se mere zavisne promenljive $u$ evaluacionim pedagoškim istraživanjima, ne mogu se dobiti informacije o pravom odnosu izmedju nezavisne i zavisne promenljive, odnoso o efektu nezavisne promenljive na zavisnu. Bez pouzdanosti mernih instrumenata $u$ evaluacionim istraživanjima nema doslednosti, tačnosti i predvidljivosti rezultata istraživanja. Odsustvo valjanosti merenja u evaluacionim istraživanjima može u potpunosti obezvrediti ta istraživanja.

4. Razvijanje i primena nacrta evaluacionih istraživanja u pedagogiji

Da bi se ocenila efikasnost nekog procesa učenja ili inovacije u kurikulumu, potrebno je uvrditi, da li se, i u kojoj meri, pomoću tog procesa proizvode željene i planirane promene, odnosno da li se njima postižu oni ciljevi obrazovnog procesa, radi kojeg je i uneta odredjena inovacija. Kao što je već rečeno, uvodjenje obrazovnih inovacija predstavlja uvodjenje nezavisne promenljive, a veličina na kojoj se želi ostvariti promena - zavisnu promenljivu.

Ali, na zavisnu promenljivu, na pojavu željenih promena, osim nezavisne promenljive mogu da utiču i mnogi drugi činioci: ekonomski, politički, sociološki, psihološki i sl. pa stoga ne možemo znati da li bi pomenu zavisne promenljive trebalo pripisati delovanju nezavisne, ili delovanju ovih drugih činilaca.

Da bi se moglo zaključivati o efektu nezavisne promenljive na zavisnu promeljivu, neophodno je na neki način, kontrolisati uticaj tih stranih činilaca. Ako taj uticaj nije kontrolisan, mogući efekti stranih činilaca na zavisnu promenljivu mogu se zameniti efektom koji na zavisnu promenljivu ima nezavisna, pa je tačan zaključak o efektu nezavisne promenljive na zavisnu nemoguć.

Za kontrolisanje uticaja stranih činilaca u prvom redu, služe nacrti evaluativnih istraživanja. Pod nacrtom istraživanja se ovde podrazumeva plan aktivnosti za istraživački projekat, kojim se do pojedinsti navodi koji će podaci, i kako biti prikupljeni, obradjeni i analizirani, tako da obezbede smisaone i značajne informacije, potrebne za donošenje odluka o daljim procesima vaspitanja i obrazovanja. Jedna od osnovnih funkcija nacrta evaluacije jeste da kontroliše efekat stranih činilaca. Nacrt evaluativnih istraživanja bi trebalo da omogući da se istraživanjem dobije odgovor na ono pitanje, radi koje je istraživanje i preduzeto.

Istraživačke strategije se medjusobno razlikuju upravo prema stepenu konrolisanja efekata stranih činilaca. Tako je na jednom ekstremu, eksperimantalna istraživačka strategija sa visokim stepenom kontrole stranih činilaca, a na drugom posmatranje u prirodnim, životnim ulsovima, i u neposrednom vaspitno-obrazovnom procesu.

Pored prirode predmeta istrživanja, objektivnih, praktičnih ograničenja i sl. izuzetno značajan uticaj na izbor istraživačke strategije imaju potrebe za infor- 
macijama onih, radi kojih se izvodi evaluaciono istaživanje. Zato su osnovna pitanja sa kojim ciljevima se organizuje evaluaciona studija.

Izbor istraživačke strategije se obično oslanja na zahtev da se novi obrazovni programi podvrgnu strogoj i temeljnoj proveri i sistematskim postupcima proveravanja da se dobiju što značajnije, valjanije i pouzdanije informacije o njihovoj obrazovnoj vrednosti. Postavljeni zahtev upućuje na strategiju koja koristi eksperimentalne nacrte istraživanja. ili strategiju koja joj je po stepenu kontrole stranih činilaca bliska. Pošto zbog niza ograničenja prakične prirode najčešće nema mogućnosti za primenu strategije s pravim eksperimentalnim nacrtima, najprikladnija je kompromisna istraživačka strategija koja uključuje takozvane „kvazi-eksperimentalne" nacrte: nacrt vremenskog niza, nacrt višestrukih vremenskih nizova, nacrt nejednake kontrolne grupe i dr. (Cempbell, 1984)

Ova strategija predstavlja strogo konzistentan pristup vrednovanju novog obrazovnog programa, obezbedjuje uslove za sistematska uporedjivanja i neke osnovne uslove za izvodjenje zaključaka o efektima nezavisne promenljive na zavisnu, tj. o uticaju novog obrazovnog programa na planirane rezultate učenja. Ta strategija se bira u nastojanju da se subjektivno, pristrasno, intuitivno u oceni vrednosti novog programa svede na što je moguće manju meru.

5. Prikupljanje, obrada i tumačenje podataka

Kada se prema odabranom nacrtu evaluativnih pedagoških istraživanja u skladu sa ciljevima evaluacije, upotrebom odgovarajućih instrumenata na odabranim uzorcima prikupe sirovi podaci, pristupa se obradi i analizi tih podataka, kao i tumačenju dobijenih rezultata. Izbor postupaka obrade i analize podataka odredjen je ciljevima evaluacionih istraživanja, prirodom odabranog nacrta istraživanja, nivoom merenja promenljivih, vrstom i veličinom uzorka i nizom drugih činilaca. 6. Validacija istraživanja

Pod validacijom istraživanja se podrazumeva sistematski, kritički i kontrolisani proces sticanja informacija potrebnih za ocenjivanje valjanosti podataka. Nema jednog jedinstvenog pojma valjanosti podataka, te je opravdano govoriti o pluralizmu pojmova valjanosti. Valjanost podataka dobijenih na nekom nivou merenja može se ticati pitanja š ta se mer $i$, ali i pitanja pove zanos $t i$ rezultata merenja sa nekim spoljašnjim kriterijumom.

Valjanost podataka dobijenih merenjem se može odrediti kao proporcija totalne varijanse (umanjene za varijansu greške) u skupu rezultata merenja značajne za svrhu radi koje su ti rezultati prikupljeni. Mala varijansa greške je nužan, ali ne i dovoljan uslov valjanosti, jer preostala proporcija totalne varijanse sadrži dva činioca: sistematsku značajnu i sistematsku beznačajnu varijansu. Sa dobrim razlozima istraživači naglašavaju da valjanost nije unutrašnje svojstvo postupka merenja, već složena i dinamička funkcija svrhe u koju se merenje koristi, situacije ukojoj se obavlja i uzorka na kojem se vrši. Uverenost da se valjanost merenja i sama može neposredno meriti nema opravdanja, ona nije predmet merenja, već predmet prosudjivanja na osnovu svedočanstva koje uzima u obzir svrhu, siutacije, uzroke i druge važne činioce. U tom smislu možemo govoriti o sadržajnoj, 
pojmovnoj i empirijskoj valjanosti. Empirijska valjanost se tiče povezanosti rezultata merenja neke promenljive sa nekim spoljašnjim kriterijumom $i$ iskustveno se odredjuje kao korelacija izmedju njih. Koeficijent te korelacije se naziva koeficijentom valjanosti.

$\mathrm{Na}$ osnovu pregledno ostvarene analize procesa pedagoških evaluacionih istraživanja, očigledno je da se tu rada o specifičnim, dinamičnim i kompleksnim empirijskim istraživanjima, koja moraju imati solidnu teorijsku osnovu, i koje moraju organizovati oni koji poseduju solidno pedagoško-metodološko obrazovanje.

Polazeći od toga da je kvalitetna evalacija fundamentalni proces na osnovu koga se može procenjivati kvalitet obrazovanja, procesa učenja i kreirati strategija njihovog unapređenja na univerzitetskom nivou, problem našeg istraživanja je bio utivrditi upravo karakteristike evaluacije koja se ostvaruje na visokoškolkim ustanovama i njenu funkcionalnost.

Cilj empirijskog istraživanja je bio utvrditi da li evaluacija koja se ostvaruje na univerzitetu ispunjava svoja dva osnovna zadatka i to:

a. Da li obezbeđuje kvalitetnu povratnu informaciju o ostvarenosti ciljeva i ishoda pojedinog programa i o karakteristikama kompetentnosti studenata koji su učestvovali u tom programu, $\mathrm{i}$

b. Da li obezbeđuje univerzitetskom nastavniku kvalitetnu povratnu informaciju o indikatorima kvaliteta procesa poučavanja, kako bi mogao donositi obrazovne odluke i unapređivati proces obrazovanja na univerzitetu.

U tu svrhu korišćena su dva instrumenta, Evaluacioni list- sumativni, kojim svake godine evaluairaju studenti rad profesora na univerzitetu, i upitnik o unapređenju kvaliteta studiranja na univerzitetu - formativni. koji je imao slična pitanja, ali je negova svha bila drugačije definisana, i on je primenjen u toku školske godine. Ideja je bila da se kvalitet evaluacije ispita nivoom saglasnosti nalaza, na ova dva istraživača instrumenta. Uzorak je činilo ukupno 257 studenata Banjalučkog univerziteta, a obuhvaćeni su Filozofski fakultet i Prirodno-matematički fakultet. Isti studenti su ispitani dva puta, jednom u toku školske godine i drugi put na kraju godine ( redovna godišnja evaluacija)

Oba upitnika konstruisana su od pet grupa pitanja, koja se odnose na evaluaciju sadržaja programa prema kriterijumima: savremenosti, podsticajnosti, povezanosti programa sa praksom, povezanosti programa sa prethodnim znanjima studenata, i nivou uvažavanja individualnnih obrazovnih potreba studenata.

Prosečna vrednost procene savremenosti sadržaja programa prema prvom upitniku, je 4,69 ili studenti smatraju da su sadržaji: veoma ili prilično savremeni. Na skali vrednosti pondiranih odgovora (od 1 do 5), to su maksimalne vrednosti, iskazane ocenama 5 i 4 . Na osnovu 257 upitnika koje su ispunili studenti njih $88,8 \%$ smatra da su sadržaji studija na ovim programima savremeni. Ostalih $11,3 \%$ smatra da su sadržaji delimično, malo ili nimalo savremeni. Očigledno je, da je statistički značajniji broj studenata potpuno zadovoljan aktuelnošću sadržaja koji se proučavaju u okviru svih pet programa. Podaci su pokazali da je samo $0,4 \%$ studenata smatra da sadržaji studija uopšte nisu savremeni a 1,6\% studenata smatra da su veoma malo savremeni. 
Tabela 1. Komparativni prikaz rezulata evaluacije programa studija, u oba upitnika

\begin{tabular}{|l|c|c|c|c|}
\hline Evaluacija programa & $\begin{array}{c}\text { Upitnik 1 } \\
\mathrm{N}\end{array}$ & $\begin{array}{c}\text { Upitnik 1 } \\
\text { Mean }\end{array}$ & $\begin{array}{c}\text { Upitnik 2 } \\
\mathrm{N}\end{array}$ & $\begin{array}{c}\text { Upitnik 2 } \\
\text { Mean }\end{array}$ \\
\hline $\begin{array}{l}\text { 1. Koliko su sadržaji, ponuđeni na } \\
\text { ovom programu savremeni }\end{array}$ & 257 & 4,69 & 240 & 3,20 \\
\hline $\begin{array}{l}\text { 2. Koliko su ponuđeni sadržaji } \\
\text { podsticajni }\end{array}$ & 257 & 4,58 & 240 & 3,18 \\
\hline $\begin{array}{l}\text { 3. Koliko su sadržaji neposredno ili } \\
\text { posredno vezani sa praksom }\end{array}$ & 257 & 4,55 & 240 & 2,33 \\
\hline $\begin{array}{l}\text { 4. Koliko su sadršaji vezani za } \\
\text { prethodna znanja u ovoj oblasti }\end{array}$ & 257 & 4,54 & 240 & 3,19 \\
\hline $\begin{array}{l}\text { 5.Koliko je ovaj program odgovorio } \\
\text { vašim potrebama }\end{array}$ & 257 & 4,34 & 240 & 2,68 \\
\hline
\end{tabular}

Međutim, ukoliko pogledamo rezultate na drugom upitniku, onda dobijamo potpuno drugačije rezultate evaluacije. Prosečna vrednost savremenosti sadržaja je svega 3,20 ili prema skali procene oni su samo delimično savremeni. Već na ovom prvom indikatoru razlika u proceni je toliko velika, da se postavlja pitanje pouzdanosti evaluacije.

Na pitanje koliko su ponuđeni sadržaji podsticajni za profesionalni razvoj, prosečna vrednost svih dobijenih odgovora studenata prema prvom upitniku je 4,58. što znači da prevladavaju odgovori visokih pozitivnih vrednosti. Od 257 upitnika (Tabela 2.) u vezi podsticajnosti sadržaja programa, $83,2 \%$ studenata smatra da sadržaji motivišuće deluju na njihov profesionalni razvoj. Očigledno je, da je prosečna vrednost podsticajnosti sadržaja nešto niža, od prosečne vrednosti ocene suvremenosti tih sadržaja. Međutim na drugom instrumentu ta prosečna vrednost podsticajnosti je još niža i ona iznosi svega 3,18.

Na pitanje koliko su sadržaji neposredno ili posredno vezani sa praksom, prosečna vrednost dobijenih procena u prvom upitniku je 4,55. Iako je prosečna ocena visoko pozitivna, istovremeno to je i kriterij na kome su studenti izrazili u najvećem procentu svoje nezadovoljstvo, kategorijom primjenljivosti sadržaja u praksi. Ovde se i dalje otvaraju pitanja vezana za: objektivne uslove i mogućnosti primene znanja i veština koje studenti dobijaju u okviru ovih programa, jer su u realnosti moguće velike diskrepancije, između onoga što studenti dobijaju, i različitosti uslova upraksi, u kojoj će primenjivati svoja znanja. U drugom upitniku prosečna vrednost povezanosti sadržaja sa prakom prema stavovima studenata je samo 2,33.

Na pitanje koliko su ponuđeni programi vezani za prethodna iskustva i znanja studenata u ovoj oblasti, prosečna vrednost dobijenih odgovora iznosi 4,54 i ona je najniža u odnosu na sve ostale pokazatelje kvaliteta programa i sadržaja, i ona ukazuje na potrebu dodatnih intelektualnih ulaganja i aktivnosti kod određenog broja studenata, čija su predznanja u ovoj oblasti bila niža, od onih koje su kreatori program pretpostavljali da postoje kod budućih polaznika. Zbog toga, gotovo 
jedna petina studenata procenjuje sadržaje neusklađenim sa njihovim predznanjima u ovoj oblasti, i ukazuje na probleme integrisanja i povezivanja novih sadržaja sa postojećim. Na upitniku br. 2 rezultati pokazuju da je prosečna vrednost samo 3,19.

Na pitanje u kojoj meri je program koji studiraju odgovorio studentskim obrazovnim potrebama i aspiracijama, prosečna vrednost odgovora je 4,34. Po rangu ova kategorija procene sadržaja programa je na drugom mestu, ali veoma blizu ocena kvaliteta programa studija koji se odnose na praktičnu primjenljivost sadržaja, i na podsticajnost sadržaja. Relativno je ovde i manji broj studenata nezadovoljnih, i to svega $14,0 \%$, slično negativnoj oceni savremenosti programa $11,3 \%$. U odgovorima na ovo pitanje na drugom upitniku, programi studija odgovaraju intelektualnim potrebama i aspiracijama studenata samo za 2,68 studenata.

Očiglednost razlike u rezultatima evaluacije između prvog i drugog upitnika još je evidentnija kada se ti rezultati i grafički prikažu:

Tabela 2. Komparacija evaluacionih rezultata između prvog i drugog upitnika

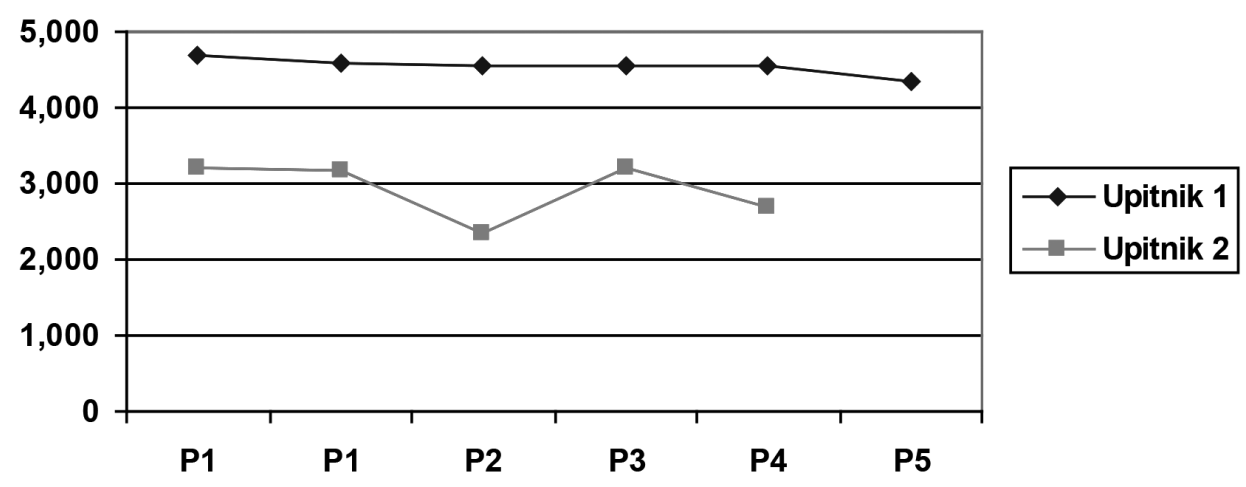

Dobijeni podaci iz dosadašnjih evaluacija nisu ispunjavali ni jedan od kriterijuma kvalitetne evaluacije: ni sa stanovišta valjanosti: procena se nije odnosila na funkciju i ciljeve evaluacije, objektivnosti, koja bi se manifestovala u vidu visokog stepena slaganja rezultata dobijenih primenom različitih instrumenata u empijskom istraživanju (između prvog i drugog upitnika), što se u našem istraživanju nije dogodilo, sa stanovišta pouzdanosti (isti studenti su za iste programe u relatino kratkom vremenskom razmaku davali potpuno različite vrednosne ocene), niti sa stanovišta (osetljivosti) procena studenata je jako varirala i bila subjektivna.

\section{ZAKLJUČCI}

Postojeće evaluacije na univerzitetskim ustanovama su samo formalne, i ne doprinose postavljenim ciljevima evaluacije. Neophodno je obezbediti kontinui- 
ranu procenu kvaliteta univerzitetskih programa, i trajno praćenje ostvarenosti ciljeva, ishoda i kompetencija kod studenata.

Pored toga, treba uspostaviti i internu evaluaciju i samoevaluaciju, kao zajednički proces studenata i nastavnika i zajedničku odgovornost, koja bi po svojim karakteristikama bila neformalna, trajna, periodična, sekvencijalana, ali po svojim rezultatima suštinska.

Prof. Dr Milka Oljača

Prof. Dr Svetlana Kostović

\section{EVALUATION OF EVALUATION IN HIGHER EDUCATION}

\section{SUMMARY}

Evaluation implies procedures for the analysis monitoring and evaluation, the level of achievement of the set objectives, and undertaking of corrective actions, if the process shows that the objectives and tasks of education are not efficiently implemented. The evaluation is a complex process that should involve all educational dimensions, i.e. not only results, but every stage of the process from the standpoint of students, teachers, learning process conditions, quality of work of educational institutions, and characteristics of its relationships with the social environment. In that sense, three evaluation functions could be distinguished: standards setting, measurement and analysis of the achieved results in relation to the adopted standards and creation of possible directions and activities of further successful work.

\section{LITERATURA}

Alkin M.C. (Ed) (2004). Evaluation root: Tracing theorists views and influences. Thousand Oaks, CA:Sage.

Brown, M. i sur (2003). Reflective practice. U: Fry i sur. (2003) A handbook for teaching and learning in higher education. Second edition. London: Kogan page.

Campbell, D. T. (1984). Can we be scientific in applied science? In R. F. Connor,D. G. Altman, \& C. Jackson (Eds.), Evaluation studies review annual (Vol. 9,pp. 26-48). Newbury Park, CA: Sage

Cohen, L., Manion, L., i Morrison, K. (2001). Research methods in education (5. izdanje). London i New York: Routledge/Falmer.

Costa, A., Kallick, B. (1993). Through the Lens of a Critical Friend. Educational Leadership 51(2) 49-51.

Darling-Hammond, L. \& Bransford, J. (2005). Preparing Teachers for a Changing World: What Teachers should Learn and Be Able to Do. San Francisco: Jossey-Bass.

Darling-Hammond, L. ( 2011) Evaluating teacher Evaluation: We Know About Value-Added Models and Other Methods. Phi Delta Kappan

Day, C. (1999). Developing Teachers: The Challenges of Lifelong Learning.London: Falmer Press. Evaluation - ein vielschichtiges Konzept Begriff und Methodik von Evaluierung und Evaluationsforschung. Empfehlungen für die Praxis , Helmut Kromrey (2001) 
Fry, H., Ketteridge, S. (2003). Theaching Portfolios. u Fry i sur. (2003) A handbookfor teaching \& learning in higher education. Second edition. London: Kogan page.

Fulerton, H. (2003). Observation of teaching. U: Fry i sur. (2003) A Handbook for Teaching and Learning in Higher Education. Second edition. London: Kogan page.

Hounsell, D. (2003). The evaluation of teaching. U : Fry i sur. (2003) A handbook for teaching \& learning in higher education. Second edition. London: Kogan page.

Jean McNiff \& Jack Whitehead (2006). All You Need to Know About Action Research.London: Sage

Landesinstitut für Schulentwicklung (2007): Qualitätsicherung und Evaluation, Stuttgart

Meyer, J. \& Norton, L. (2004) Editorial. Metalearning in higher education. Innovations in Education and Teaching International, 41, 4, 387- 390

Norton, L., Richardson, J.T.E., Hartley, J., Newstead, S. \& Mayes, J. (2005) Teachers' beliefs and intentions concerning teaching in higher education. Higher Education, 50,4, 537-571

Popham, J. W. (2001). The truth about testing: An educator's call to action. Alexandria, VA: ASCD.

Scriven, Michael (1967). “The methodology of evaluation”. In Stake, R. E. Curriculum evaluation. Chicago: Rand McNally. American Educational Research Association (monograph series on evaluation, no. 1 .

Stake R.E (1977) The countenance of educational evaluation, u knjizi Bellack H.M Kleihard ed. Curriculum and evaluation, Berkeley, CA Mc Cutchan

Stake R.E (2010) Qualitative research studyng how things work, New York, Guilford Publications Inc.

Stake, R. E. (2004). Standards-based and responsive evaluation.Thousand Oaks,CA: Sage.

Stufflebeam D.L. Webster W.J. (1980) An Analysis of Alternative Aproaches to Evaluation, Educational Evaluation and Policy Analusis, 2 (3), 5-20.

Stufflebeam, D. L. (Ed.). (2001). Evaluation models (New Directions for Evaluation, Vol. 89). San Francisco: Jossey-Bass. 